\title{
BMJ Open Pain and its impact on functioning and disability in manual wheelchair users with spinal cord injury: a protocol for a mixed-methods study
}

\author{
Mokgadi Kholofelo Mashola (D) ,, ${ }^{1,2}$ Elzette Korkie, ${ }^{1}$ Diphale Joyce Mothabeng ${ }^{1}$
}

To cite: Mashola MK, Korkie E, Mothabeng DJ. Pain and its impact on functioning and disability in manual wheelchair users with spinal cord injury: a protocol for a mixedmethods study. BMJ Open 2021;11:e044152. doi:10.1136/ bmjopen-2020-044152

- Prepublication history for this paper is available online. To view these files, please visit the journal online (http://dx.doi. org/10.1136/bmjopen-2020044152).

Received 24 August 2020 Revised 05 November 2020 Accepted 30 November 2020

A) Check for updates

(c) Author(s) (or their employer(s)) 2021. Re-use permitted under CC BY-NC. No commercial re-use. See rights and permissions. Published by BMJ.

${ }^{1}$ Department of Physiotherapy, School of Healthcare Sciences, University of Pretoria, Pretoria, South Africa

${ }^{2}$ Department of Physiotherapy, School of Therapeutic Sciences, University of the Witwatersrand, Johannesburg, South Africa

Correspondence to

Mokgadi Kholofelo Mashola;

kholofelo.mashola@wits.ac.za

\section{ABSTRACT}

Introduction Approximately $80 \%$ of people with spinal cord injury experience clinically significant chronic pain. Pain (whether musculoskeletal or neuropathic) is consistently rated as one of the most difficult problems to manage and negatively affects the individual's physical, psychological and social functioning and increases the risk of pain medication misuse and poor mental health. The aim of this study is to therefore determine the presence of pain and its impact on functioning and disability as well as to develop a framework for self-management of pain for South African manual wheelchair users with spinal cord injury.

Methods and analysis Community-dwelling participants with spinal cord injury will be invited to participate in this three-phase study. Phase 1 will use a quantitative, correlational design to determine factors related to pain such as pectoralis minor length, scapular dyskinesis, wheelchair functioning, physical quality of life, community reintegration and pain medication misuse. Demographic determinants of pain such as age, gender, type of occupation, completeness of injury and neurological level of injury will also be investigated. Participants with pain identified in phase 1 will be invited to partake in a qualitative descriptive and contextually designed phase 2 to explore their lived experience of pain through in-depth interviews. The results of phases 1 and 2 will then be used with the assistance from experts to develop a framework for self-management of pain using a modified Delphi study. Data analysis will include descriptive and inferential statistics (quantitative data) and thematic content analysis (qualitative data).

Ethics and dissemination Approval for this study is granted by the Faculty of Health Sciences Research Ethics Committee of the University of the Pretoria (approval number 125/2018). This study is registered with the South African National Health Research Database (reference GP201806005). This study's findings will be shared in academic conferences and published in scientific peerreviewed journals.

\section{INTRODUCTION}

Pain after spinal cord injury (SCI) is common and well documented in developed countries with prevalence rates ranging from $11 \%$ to $94 \% .{ }^{12}$ Two-thirds of people with SCI (PWSCI)
Strengths and limitations of this study

- This study is limited to participants residing in in land provinces $500 \mathrm{~km}$ from their discharging rehabilitation facility, thus the findings may not be generalised to the coastal regions of South Africa.

- This study focuses on the presence of pain in a focused group (paraplegia) in order to gain insight into the development of pain in manual wheelchair users.

- Factors related to upper limb pain may not be generalised to people with tetraplegia, who have upper limb muscle imbalances due to the spinal cord injury.

- Both quantitative and qualitative data will be explored in this study, giving rich information necessary for the development of a self-management framework of pain.

reported neuropathic pain in a South African study, with almost half reporting the neuropathic pain as a significant problem. ${ }^{3}$ Neuropathic pain is caused by a primary lesion or a dysfunction in the nervous system, as seen in $\mathrm{SCI}^{4}$ and the prevalence rates range as high as $63 \%-91 \% .^{2}$ SCI-related neuropathic pain is an example of central neuropathic pain and is often characterised by spontaneous, persistent and constant pain that described as abnormal sensations such as burning, tingling and stabbing as well as pins and needles. ${ }^{5}$ Changes in the nerve cells close to the level of injury (such as hyper excitability of the spinal neurons) lead to abnormal spontaneous neuronal activity and spontaneous pain, particularly in the dorsal horn neurons immediately above the level of injury. ${ }^{67}$ The mechanisms of the pain include increased responses to peripheral stimulation, level of background activity and prolonged firing following a stimulus. ${ }^{6}$ Spontaneous activity is increased by both noxious and non-noxious stimuli to the spinal neurons close to the level of injury after SCI. ${ }^{7}$ Pain may persist 
despite removal of a spinal cord above the level of injury, suggesting that changes in the brain structure may also contribute to pain in PWSCI. ${ }^{6}$ An SCI is associated with changes in glial cell activation in the thalamus ${ }^{8}$ and there is a shift in cortical representation of a body region when neuropathic pain is present, thus demonstrating a link between plastic changes in the brain and the presence of SCI-related neuropathic pain. ${ }^{6}$

Pain experienced by PWSCI can coexist above, at and below the neurological level of injury (NLI) ${ }^{9}$ Musculoskeletal shoulder pain is the most common nociceptive pain in the upper limbs for $\mathrm{PWSCI}^{10}$ with prevalence rates ranging from $32 \%$ to $78 \% .^{11}$ For PWSCI to be able to participate in their communities, they must be able to perform wheelchair-related functional tasks, such as wheelchair transfers and wheelchair propulsion up incline surfaces, which are risk factors leading to shoulder pain. ${ }^{11}$ These wheelchair activities repetitively load the shoulder joint, reducing the subacromial space and impinging the subacromial structures. ${ }^{12}$ Shoulder dysfunction can be caused by various factors including a decreased pectoralis minor muscle (PMm) length, due to adaptive shortening or scapular dyskinesis (altered scapular motion and position). ${ }^{13}$ Scapular dyskinesis and PMm length will be determined in this study as scapula performance plays a vital role in effective shoulder position, stability, movement and muscle performance during wheelchair activities. ${ }^{14}$ The upper limbs are used as the primary mode of mobility and transfers, and as such, PWSCI who use manual wheelchairs are unable to rest their upper limbs in the presence of pain. ${ }^{315}$ The inability to rest the upper limbs may force PWSCI to endure the pain while trying to participate with others. ${ }^{16}$ Poor upper limb function as a result of pain negatively affects participation in daily life activities. ${ }^{17}$ Perceptions of pain may be intense and reported as severe to extreme and interfering with activities of daily living, more so than the SCI itself. ${ }^{2}$ PWSCI who report severe pain levels may refrain from fully engaging in their community due to the pain levels ${ }^{18}$ thus negatively impacting their perception of health $^{3}$; function during wheelchair skills; quality of life (QOL) and community participation ${ }^{19}$ as well as affect their cognitive and emotional function. ${ }^{20}$

The management of pain in PWSCI is complex due to the different underlying mechanisms of pain, ${ }^{20}$ and the management may further be complicated by a variety of emotional, behavioural and social factors that can negatively affect the experience of pain. ${ }^{21}$ Treatment for SCI-related pain predominantly includes pharmacological, surgical or therapeutic interventions, ${ }^{20}$ with fewer interventions addressing the psychosocial aspects related to pain. Despite the available interventions, PWSCI still report that significant pain relief is difficult to achieve, with pharmacological treatments providing minimal pain relief. ${ }^{2}$ The use of medication may be chronic and requires accessibility to funds to visit a general practitioner to receive a prescription for scheduled drugs or funds to buy the drugs over-the-counter at registered pharmacies. PWSCI may be burdened with the cost of pain-relief medication and those with financial constraints may proceed with daily life while experiencing pain. Side effects are common with continuous use of medication, such as drowsiness, nausea and gastrointestinal problems. There are increasing rates of chronic pain medication misuse (PMM) and overdose deaths from use of prescribed opioid analgesics in the general (able-bodied) population over the past decade. The increasing rates are estimated at $3 \%$ to $78 \% .{ }^{22}$ Almost $30 \%$ of PWSCI are at risk of problematic PMM and $17.6 \%$ at risk of more serious aberrant behaviours. ${ }^{22}$ Pain experiences are associated with risk of PMM and those with greater perceived interference of pain on functioning have greater risk of misuse. ${ }^{22}$ Research on prevalence and individual characteristics associated with PMM among PWSCI is limited, therefore understanding and identifying risks associated with PMM are critical.

Despite the challenges, management of pain is essential, and without intervention, PWSCI may experience additional losses in function and community mobility. ${ }^{23}$ Lack of information regarding how to alleviate the pain once present, reduced accessibility to health facilities, financial constraints and accepting that this is the way of life after SCI are only a few reasons why PWSCI would endure living with pain. In some cases, the pain can be so severe that PWSCI are isolated from society as they are unable to propel their own wheelchairs. This may lead to them unwilling to ask for assistance to not infringe on their autonomy or perceive themselves as a burden to their family and friends, thus negatively impacting their QOL. ${ }^{19}$ Each type of intervention provided by healthcare professionals comes at a financial cost, and PWSCI will use interventions most financially accessible. Visiting a healthcare professional weekly for pain-relieving interventions may not be feasible and therefore calls for the development of self-management methods to relieve pain. Self-management programmes are increasing in popularity and several self-management pain interventions show positive outcomes for PWSCI, ${ }^{24}$ particularly for individuals from low-income households. ${ }^{25}$ Selfmanagement is an important part of any model of care and refers to an individual's ability to manage not only their symptoms and treatment but also their physical and psychological consequences after a chronic condition. ${ }^{24}$ Self-management includes tasks such as medical, role and emotional management as well as decision-making, action-taking, problem solving and self-tailoring skills as well as skills needed to form a client-healthcare provider partnership. ${ }^{25}$

It is important to understand the factors that contribute to pain in PWSCI so that specific and appropriate intervention strategies can be developed to minimise the impact of pain on function as well as to prevent the occurrence of other secondary health conditions. ${ }^{17}$ This proposed study therefore aims to determine the presence of pain and its association with factors such as PMm length, scapular dyskinesis, pain medication use, wheelchair skills, 
community participation and QOL as well as to develop a framework for self-management of pain for PWSCI.

\section{METHODS AND ANALYSIS}

This study is designed as a mixed-methods study with three phases. Phase 1 will be a quantitative correlational study, phase 2 will be a qualitative study that seeks to explore the perceptions and experiences of pain by PWSCI. Results from phases 1 and 2 will then be used in phase three to develop a framework for pain self-management using a modified Delphi study. Table 1 gives the summary of the methodology across the three phases of the study.

\section{PHASE 1}

The aim of phase 1 is to determine the presence of pain and its impact on functioning and disability in manual wheelchair users (MWUs) with SCI. PWSCI with paraplegia, who use manual wheelchairs and discharged for at least 6 months from six rehabilitation institutions admitting PWSCI in Gauteng, South Africa will be included in this study, irrespective of the presence of pain. Paraplegia is a type of SCI that results in partial or full loss of sensory and/or motor function of the trunk and lower limbs. ${ }^{26}$ The upper limbs, including hand function is preserved and participants will be able to manually propel a wheelchair as well as have intact innervation of the PMm (which is innervated by C8-T1). The 6-month discharge period allows for achievement of optimum level of independency and for soft tissue changes (such as muscle shortening that could occur due to prolonged wheelchair activities). Consecutive sampling method will be used, whereby all adult PWSCI will be enrolled as they consent to participate in the study.

The sample size was determined by the instrumental variable (pain). At least $35 \%$ of MWUs were suspected to experience general pain, which was a function of no more than eight variables in this study. The variables included age, gender, years living with SCI, NLI, completeness of injury, type of occupation, PMm length and the presence of scapular dyskinesis. The sample size was derived from the events per variable (EPV) approach ${ }^{27}$ where EPV $>5$, that is, number of events $>5 \times 8=40$. Hence sample size equals $40 / 0.35$, that is, at least 115 participants. Consenting participants who are readmitted to hospital, or move residences beyond $500 \mathrm{~km}$ radius of their hospital of discharge at the time of data collection, will be excluded from the study.

\section{Study procedures}

The researcher will peruse the databases of the different rehabilitation institutions to identify the potential participants and will contact each one via telephone to invite them to participate in the study. The researcher will travel to all the consenting participants and they will sign an informed consent form, keeping in line with the ethical principles contained in the current version of the World
Medical Association Declaration of Helsinki. Data will be collected using the measurement tools described in table 2 .

\section{Data analysis}

Descriptive statistics will report mean, SD, median, interquartile range, data frequencies, percentages and 95\% CIs. Summary statistics will be reported for the overall group and the factors associated with pain, to be included in the instrumental-variables regression, will be determined using multivariable logistic regression. These factors along with sociodemographic information will then be employed to fit the instrumental-variables regression to the observed data. Testing will be done at the 0.05 level of significance.

\section{PHASE 2}

The aim of phase 2 to explore the perceptions and experiences of MWUs regarding pain. Purposive/judgement sampling will be used to ensure that the sample is composed of participants who feature the most characteristic, representative or typical attributes of the population who report the presence of pain. ${ }^{28} \mathrm{~A}$ fixed sample size will not be predetermined: key informants from phase 1 will be added to the study until data saturation is reached as per the principles of qualitative data collection, ${ }^{28}$ with a minimum of 15 participants.

\section{Study procedures}

Individual semistructured interviews will be used to collect data and five main questions will be addressed in the interviews. To describe the experience of pain since the SCI; if they think the pain will affect their future if at all; pain education from a healthcare professional; coping strategies that are used to manage the pain as well as treatment ideas of what they think can be added by healthcare professionals. The first question will be a broad open-ended question to give participants the opportunity to be comfortable in the interview process as well as to allow them to reflect about their life since experiencing SCI-related pain. ${ }^{29}$ The interview will be recorded using a digital voice recorder. An independent transcriber will transcribe all the recorded data verbatim.

\section{Data analysis}

All transcribed interviews will be compared with the audiotaped recordings to verify their accuracy. ${ }^{30}$ NonEnglish transcripts will be translated into English before coding by an independent translator. An independent translator who has not seen the original transcripts will translate the translated transcripts back into its original language in order to verify the content of the translated transcripts. Thematic content analysis will be used to identify themes from the qualitative data and data will be coded by the researcher and the supervisor, where foci which are similar will be categorised and subcategorised using MAXQDA, and thereafter themes will be identified 
Table 1 Summary of the study

\section{Phase 1}

Objectives

To determine:

1. The presence of musculoskeletal pain.

2. The presence of neuropathic pain.

3. The association of musculoskeletal shoulder pain and the following internal factors: (a) pectoralis minor muscle length $b$ ) scapular dyskinesis.

4. The impact of pain on wheelchair function.

5. The impact of pain on QOL.

6 . The impact of pain on community reintegration.

7. The risk of pain medication misuse.

8. The sociodemographic and injury profile of MWUs who complain of pain.
Phase 2

\section{Phase 3}

1. To ascertain how MWUs experience life with the presence of pain.

2. To determine strategies used by MWUs to cope with the pain.

3. To determine how MWUs feel pain may affect their future if at all.

4. To obtain suggestions from MWUs on how pain management programmes can be enhanced.
The objective is to use the results of phase 1 and phase 2 to guide the development of a framework for the selfmanagement of pain.
Source of participants

Patient records (databases) of five hospitals and rehabilitation units that admit PWSCl
MWUs who report the presence of pain in phase 1
$\mathrm{SCl}$ network from SASCA, pain management and neurology rehabilitation special interest groups of SASP and PainSA

$\begin{array}{lll}\text { Design } & \text { Quantitative, cross-sectional design } & \text { Qualitative, descriptive contextual design } \\ \text { Participants } & \text { MWUs with T2 paraplegia and below } & \begin{array}{l}\text { MWUs who reported the presence of pain } \\ \text { in phase 1 }\end{array}\end{array}$
in phase 1

Modified Delphi study

Health professionals in the field of $\mathrm{SCl}$ rehabilitation and pain management in both academia and clinical care.

\begin{tabular}{|c|c|c|c|}
\hline Setting & \multicolumn{2}{|c|}{ Participants' homes or private offices } & Online platform: REDCap \\
\hline Sample size & 115 MWUs & $15-20$ until data saturation is met & Seven to 14 \\
\hline $\begin{array}{l}\text { Inclusion } \\
\text { criteria }\end{array}$ & $\begin{array}{l}\text { All consenting MWUs irrespective of } \\
\text { type, cause and completeness of SCl. }\end{array}$ & MWUs must report the presence of pain & $\begin{array}{l}\text { Health professionals in } \\
\text { academia: PhD or near } \\
\text { completion } \\
\text { Health professionals in } \\
\text { clinical care: } 10 \text { years } \\
\text { experience in their } \\
\text { respective fields }\end{array}$ \\
\hline $\begin{array}{l}\text { Exclusion } \\
\text { criteria }\end{array}$ & $\begin{array}{l}\text { MWUs readmitted during the data } \\
\text { collection period }\end{array}$ & Incomplete interviews & $\begin{array}{l}\text { Incomplete ratings at the } \\
\text { end of the data collection } \\
\text { period }\end{array}$ \\
\hline $\begin{array}{l}\text { Procedures and } \\
\text { instrumentation }\end{array}$ & $\begin{array}{l}\text { Outcome measures described in } \\
\text { table } 1\end{array}$ & $\begin{array}{l}\text { Individual, in-depth, semistructured } \\
\text { interviews recorded on a digital recorder }\end{array}$ & $\begin{array}{l}\text { Scoring of the items in } \\
\text { the proposed framework }\end{array}$ \\
\hline Data analysis & $\begin{array}{l}\text { Descriptive statistics } \\
\text { Appropriate tests of association } \\
\text { Instrumental-variables regression } \\
\text { using multivariable logistic regression. }\end{array}$ & $\begin{array}{l}\text { Identify substantive statements } \\
\text { Cross-case analysis } \\
\text { Separate coding done to identify themes, } \\
\text { subthemes and categories }\end{array}$ & $\begin{array}{l}\text { In three components: } \\
\text { First component: } \\
\text { consensus agreement } \\
\text { Second component: } \\
\text { importance agreement } \\
\text { Third component: } \\
\text { rotational modification to } \\
\text { the Delphi process }\end{array}$ \\
\hline
\end{tabular}

.MWUs, manual wheelchair users; PhD, doctor of philosophy; PWSCI, people with spinal cord injury; QOL, quality of life; SASCA, Southern African Spinal Cord Association; SASP, South African Society of Physiotherapy; SCI, spinal cord injury. 
Table 2 Data collection tools for phase 1

\begin{tabular}{|c|c|c|c|}
\hline Data collected & $\begin{array}{l}\text { Outcome } \\
\text { measurement tool }\end{array}$ & Description of outcome measurement tool & $\begin{array}{l}\text { Psychometric properties of } \\
\text { outcome measurement tool }\end{array}$ \\
\hline Shoulder pain & $\begin{array}{l}\text { Wheelchair User's } \\
\text { Shoulder Pain Index }\end{array}$ & $\begin{array}{l}\text { Assesses the intensity of pain during activities } \\
\text { of daily living. Scores range from } 0 \text { to } 150 \text { with a } \\
\text { minimal detectable change of } 5.1 \text { points. }\end{array}$ & $\begin{array}{l}\text { High internal consistency } \\
\text { (Cronbach alpha }=0.97) \text { and a high } \\
\text { test-retest reliability intraclass } \\
\text { correlation coefficient }\left(\text { ICC) }=0.99^{36} \text {. }\right.\end{array}$ \\
\hline $\begin{array}{l}\text { Neuropathic } \\
\text { pain }\end{array}$ & $\begin{array}{l}\text { Douleur Neuropathique } \\
4\end{array}$ & $\begin{array}{l}\text { Determines the presence of neuropathic pain } \\
\text { through symptoms, characteristics and location } \\
\text { of pain in relation to the level of the injury. }\end{array}$ & $\begin{array}{l}\text { High inter-rater reliability values of } \\
\text { between } 0.70 \text { and } 0.96^{37} \text {. }\end{array}$ \\
\hline $\begin{array}{l}\text { Average pain } \\
\text { severity }\end{array}$ & Numeric Rating Scale & $\begin{array}{l}\text { Measures the subjective intensity of an } \\
\text { individual's pain. Is an } 11 \text {-point Likert scale } \\
\text { where ' } 0 \text { '=no pain and ' } 10 \text { '=the most intense } \\
\text { pain imaginable experienced in the last } 24 \text { hours. }\end{array}$ & $\begin{array}{l}\text { Adequate construct and content } \\
\text { validity in } \mathrm{SCl} \text { population } \mathrm{r}=0.38^{38} \\
39\end{array}$ \\
\hline $\begin{array}{l}\text { Pain medication } \\
\text { misuse }\end{array}$ & $\begin{array}{l}\text { Pain Medication } \\
\text { Questionnaire }\end{array}$ & $\begin{array}{l}\text { Assesses the risk for pain medication misuse in } \\
\text { individuals who report pain }\end{array}$ & $\begin{array}{l}\text { Adequate construct and content } \\
\text { validity. Cronbach's alpha of } \\
0.73 \text { and } r=0.84 \text { in a test-retest } \\
\text { reliability }{ }^{40} \text {. }\end{array}$ \\
\hline Quality of life & $\begin{array}{l}\text { WHO Quality of Life } \\
\text { Assessment }\end{array}$ & $\begin{array}{l}\text { Determines quality of life and nine items (seven } \\
\text { items from the physical health domain and the } \\
\text { two overall quality of life and general health } \\
\text { items) will be used }\end{array}$ & $\begin{array}{l}\text { High reliability at } \propto=0.74-0.87 \\
\text { item-domain validity }(r=0.41-0.77) \text {, } \\
\text { correlated with the SF-36 at } \\
r=0.33-0.78) \text {. Excellent inter-rater } \\
\text { reliability }(I C C=0.84-0.93)^{42} \text {. }\end{array}$ \\
\hline $\begin{array}{l}\text { Community } \\
\text { reintegration }\end{array}$ & Normal Living Index & $\begin{array}{l}\text { Assesses an individual's reintegration to their } \\
\text { community. Both the total score=sum (points } \\
\text { all } 11 \text { items) and the adjusted score = (total } \\
\text { score) } / 110 \text { * } 100 \text { can be calculated. }\end{array}$ & $\begin{array}{l}\text { Excellent reliability coefficient } 0.97 \\
(\text { ICC } 0.97-0.98)^{43}\end{array}$ \\
\hline $\begin{array}{l}\text { Pectoralis } \\
\text { minor muscle } \\
\text { (PMm) length }\end{array}$ & $\begin{array}{l}\text { Vernier caliper INSIZE } \\
\text { CO., LTD, } 300 \mathrm{~mm}\end{array}$ & $\begin{array}{l}\text { The PMm is measured in supine together with } \\
\text { the participant's height (which will be measured } \\
\text { using a tape measure). PMm length is expressed } \\
\text { as Pectoralis Minor Index and is calculated as: } \\
\text { (PMm length }(\mathrm{cm}) / \text { height }(\mathrm{cm}) \times 100)^{13} \text {. }\end{array}$ & $\begin{array}{l}\mathrm{ICC}=0.95-0.97 ; \mathrm{SEM}=0.31- \\
0.42 \mathrm{~cm} \text {; inter-rater } \\
\text { reliability }=0.86-0.87 ; \mathrm{SEM}=0.70- \\
0.84 \mathrm{~cm}^{45} \text {. }\end{array}$ \\
\hline
\end{tabular}

$\mathrm{SCl}$, spinal cord injury.

that are related to the topic. ${ }^{31}$ Coding will take place on two separate occasions and the results between the two coders will be compared. To ensure trustworthiness of data, a field journal will be used to keep an audit trail throughout the research process, which will include detailed description of the data collection, analysis and interpretation. Debriefing sessions will take place with the study supervisors to discuss the research process, findings and data analysis.

\section{PHASE 3}

The aim of this phase is to develop a self-management framework for pain. Seven to 14 experts identified in the field of SCI and/or pain management in either academia (with a $\mathrm{PhD}$ or near completion of one) or clinical practice (with 10 years of experience) will be invited to participate in the study. The experts should also have at least one article published in a peer-reviewed journal to be included in this study. Experts will be identified from 
academic and clinical work conducted through the International Spinal Cord Society, Africa Spinal Cord Injury Network, Southern African Spinal Cord Association, South African Neurology Association, PainSA and 'Pain management' and 'Neurological rehabilitation' special interest groups of the South African Society of Physiotherapy. The researcher will contact the administrative staff of the abovementioned organisations to identify the potential experts. Once identified, the experts will be invited to participate in the study via email, where a detailed information sheet will be attached to the email to explain the study aims, process and an informed consent form which will need to be signed prior to participating in the study.

\section{Study procedures}

Our modified Delphi survey will consist of three rounds where the first two anonymous rounds will be completed using the online survey tool 'Research electronic data capture' (REDCap) to enable rapid responses and instant analysis as well as reduce the time taken to complete the surveys for professionals who often have little time at their disposal. ${ }^{32}$ In round 1 , the experts will be sent a predetermined list of treatment modalities that PWSCI can use as part of the framework for self-management of pain. This predetermined list will be derived from the existing literature through a scoping review done by the researcher, quantitative data analysed from phase 1 as well as qualitative data analysed from phase 2 of this research. Each participant will be requested to specify whether they 'agree' or 'disagree' to include the item in the framework ${ }^{33}$ and provide reasons for their scoring choice. The experts will be allowed to add any other treatment modality that is not included in the original list, and these will be scored in round 2. Agreement will be obtained if $80 \%$ of the experts agree with the inclusion of the items as recommended by the literature. ${ }^{33}$ Items that do not meet the $80 \%$ agreement will be modified according to the feedback given by the experts and redistributed in round 2. Items that reach consensus at the end of both rounds 1 and 2 will be added to the final framework. Round 3 will be a final, online, recorded audio conference meeting facilitated by the researcher to allow for expert interaction to exchange important information, clarify reasons for disagreements; present arguments in order to justify their viewpoints as well as generate alternatives for and against best practice. ${ }^{33}$ Unlike the first two rounds, round 3 will not be anonymous and experts will be encouraged to discuss the remaining items that do not reach consensus until an agreement is reached to either retain, modify or eliminate the item from the final framework. ${ }^{33}$ Items that reach consensus at the end of round 3 will also be added to the final framework and the final list of treatment modalities will be grouped according to the biological, psychological and social components of the biopsychosocial model of care.

\section{Data analysis}

Descriptive statistical analysis will be completed using SPSS V.26 statistical package. The expert's demographic data will be reported as means with SD for the continuous data. Associations and comparisons will be analysed using Fisher's exact tests and independent t-tests and/or analysis of variance (ANOVA), respectively. Agreement with statements will be summarised using median scores and measures of dispersion, in this instance IQR. For the open text box questions in the first round, thematic content analysis will be used to analyse the qualitative data. The level of significance will be tested at $\mathrm{p}<0.05$.

\section{PLANNED PATIENT AND PUBLIC INVOLVEMENT IN GUIDANCE FOR REPORTING INVOLVEMENT OF PATIENTS AND THE PUBLIC (GRIPP2) ACCORDING TO BMJ GUIDANCE}

- Chronic pain was identified by the researcher as the most common secondary health condition in PWSCI in South Africa, with negative associations with QOL and health satisfaction. These findings guided the development of this study's research question.

- PWSCI were involved as research partners (participants) who were crucial to the design of this study.

- Both government and private hospitals and rehabilitation facilities were involved in recruitment of participants to this study to include a variety of the type of patients admitted after SCI. The hospitals granted permission for the researcher to access their patient database to retrieve patient contact details to be able to invite the potential participants to participate in the study. The participants (PWSCI) will be involved in phase 1 and phase 2 of the study. Health professionals in the field of SCI and pain management will be involved in phase 3 .

- This study findings will be disseminated to all study participants via email, and the authors will present the findings at academic conferences as well as publish the results in scientific peer-reviewed journals.

\section{DISCUSSION}

The dynamic interaction between demographic factors, SCI profile, psychological status and social factors emphasises the multidimensionality of pain, making the pain experience unique and individualised. ${ }^{34}$ Understanding the determinants and consequence of pain as well as the impact of pain on functioning and disability offers insight into the development of pain and the possible risk factors, which is necessary for early and effective intervention. It is imperative to identify the various factors that contribute to the onset of pain in order to devise effective prevention and treatment. Self-management programmes are low cost and give PWSCI autonomy for their own health. Developing a self-management programme that includes psychosocial aspects related to adjustment and pain interference further highlights the importance of this study, as the programme will look beyond the current pharmacological treatments of SCI-related pain. This will contribute to the management of secondary health conditions by minimising readmission back to the hospital setting as recommended by literature, ${ }^{35}$ and thus decreasing the 
financial burden on PWSCI. Furthermore, the development of the pain self-management framework will address the current challenges faced in the rehabilitation of PWSCI, and thus positively influence curriculum changes in training physiotherapy students. This study will further assist in determining the extent pain limits in PWSCI in their daily lives and its impact on their QOL. Preventative methods can thereafter be developed to maintain the health, function and QOL of PWSCI.

\section{ETHICS AND DISSEMINATION}

This study has been approved by the Faculty of Health Sciences Research Ethics Committee of the University of the Pretoria (approval number 125/2018) and is registered with the South African National Health Research Database (reference GP201806005). Permission has been granted by the hospitals and written informed consent will be obtained from all the participants. All data from this study will be stored for a period no less than 15 years in accordance with the data safekeeping requirements of the research ethics committee. Confidentiality will be maintained and the identities of the participants will be protected by identifying them by code. The hospitals and rehabilitation facilities where the databases will be perused will have pseudonyms in any scientific report. There will be no financial cost involved for the participant to be allowed to partake in the study and participants will not be compensated for partaking in this study. This study is envisioned to be submitted for examination for the requirements of Doctorate of Philosophy in Physiotherapy. This study's findings will be shared in academic conferences as well as published in scientific peer-reviewed journals.

Acknowledgements Mrs Sonti Pilusa and Mrs Vaneshveri Naidoo for the assistance with editing the manuscripts.

Contributors MKM, EK and DJM were involved in the conception and design of the study. MKM is the PhD candidate and drafted the manuscript. EK and DJM are the supervisors who assisted in the conceptualisation of the study and reviewed this manuscript. All authors read and approved the final manuscript.

Funding This work is supported by the National Research Fund (NRF) Thuthuka grant (TTK180416321193) (from 2019 to present) and received partial funding from the Southern African Spinal Cord Association (2018). The statements made and views expressed are solely the responsibility of the authors. The funding bodies played no role in the design of the study and writing of this manuscript. Furthermore, they will play no role in the study's data collection, analysis and interpretation.

\section{Competing interests None declared.}

Patient and public involvement Patients and/or the public were involved in the design, or conduct, or reporting, or dissemination plans of this research. Refer to the Methods section for further details.

\section{Patient consent for publication Not required.}

Open access This is an open access article distributed in accordance with the Creative Commons Attribution Non Commercial (CC BY-NC 4.0) license, which permits others to distribute, remix, adapt, build upon this work noncommercially, and license their derivative works on different terms, provided the original work is properly cited, appropriate credit is given, any changes made indicated, and the use is non-commercial. See: http://creativecommons.org/ licenses/by-nc/4.0/.
ORCID iD

Mokgadi Kholofelo Mashola http://orcid.org/0000-0003-3620-5668

\section{REFERENCES}

1 Raichle KA, Hanley M, Jensen MP, et al. Cognitions, coping, and social environment predict adjustment to pain in spinal cord injury. $J$ Pain 2007;8:718-29.

2 Guy S, Mehta S, Leff L, et al. Anticonvulsant medication use for the management of pain following spinal cord injury: systematic review and effectiveness analysis. Spinal Cord 2014;52:89-96.

3 Mashola MK, Mothabeng DJ. Associations between health behaviour, secondary health conditions and quality of life in people with spinal cord injury. Afr J Disabil 2019;8:a463.

4 IASP. IASP terminology, 2019. Available: https://www.iasp-pain.org/ terminology?navltemNumber $=576 \#$

5 Mann R, Schaefer C, Sadosky A, et al. Burden of spinal cord injuryrelated neuropathic pain in the United States: retrospective chart review and cross-sectional survey. Spinal Cord 2013;51:564-70.

6 Siddall PJ. Management of neuropathic pain following spinal cord injury: now and in the future. Spinal Cord 2009;47:352-9.

7 Wang J, Kawamata M, Namiki A. Changes in properties of spinal dorsal horn neurons and their sensitivity to morphine after spinal cord injury in the rat. Anesthesiology 2005;102:152-64.

8 Masri R, Keller A. Chronic pain following spinal cord injury. Adv Exp Med Biol 2012;760:74-88.

9 Ditor DS, Latimer AE, Ginis KAM, Martin Ginis KA, et al. Maintenance of exercise participation in individuals with spinal cord injury: effects on quality of life, stress and pain. Spinal Cord 2003;41:446-50.

10 Morrow MMB, Hurd WJ, Kaufman KR, et al. Shoulder demands in manual wheelchair users across a spectrum of activities. $J$ Electromyogr Kinesiol 2010;20:61-7.

11 Rafiullah Z, Mazhar S. The prevalence of shoulder pain in spinal cord injury patients using manual wheelchair in KPK (Khyber Pakhtunkhwa). JIIMC 2017;12:101-5.

12 Lin Y-S, Boninger M, Worobey L, et al. Effects of repetitive shoulder activity on the subacromial space in manual wheelchair users. Biomed Res Int 2014;2014:1-9.

13 Rosa DP, Borstad JD, Pogetti LS, et al. Effects of a stretching protocol for the pectoralis minor on muscle length, function, and scapular kinematics in individuals with and without shoulder pain. $J$ Hand Ther 2017;30:20-9.

14 Kibler WB, Ludewig PM, McClure PW, et al. Clinical implications of scapular dyskinesis in shoulder injury: the 2013 consensus statement from the 'Scapular Summit'. Br J Sports Med 2013;47:877-85.

15 Cratsenberg KA, Deitrick CE, Harrington TK, et al. Effectiveness of exercise programs for management of shoulder pain in manual wheelchair users with spinal cord injury. J Neurol Phys Ther 2015;39:197-203.

16 Kemp BJ, Bateham AL, Mulroy SJ, et al. Effects of reduction in shoulder pain on quality of life and community activities among people living long-term with $\mathrm{SCI}$ paraplegia: a randomized control trial. J Spinal Cord Med 2011;34:278-84.

17 Moon Y, Jayaraman C, Hsu IMK, et al. Variability of peak shoulder force during wheelchair propulsion in manual wheelchair users with and without shoulder pain. Clin Biomech 2013;28:967-72.

18 Piatt JA, Nagata S, Zahl M, et al. Problematic secondary health conditions among adults with spinal cord injury and its impact on social participation and daily life. J Spinal Cord Med 2016;39:693-8.

19 Gutierrez DD, Thompson L, Kemp B, et al. The relationship of shoulder pain intensity to quality of life, physical activity, and community participation in persons with paraplegia. J Spinal Cord Med 2007;30:251-5.

20 Cardenas DD, Felix ER. Pain after spinal cord injury: a review of classification, treatment approaches, and treatment assessment. Pm R 2009;1:1077-90.

21 Tran J, Dorstyn DS, Burke ALJ. Psychosocial aspects of spinal cord injury pain: a meta-analysis. Spinal Cord 2016;54:640-8.

22 Clark JMR, Cao Y, Krause JS. Risk of pain medication misuse after spinal cord injury: the role of substance use, personality, and depression. J Pain 2017;18:166-77.

23 Mulroy SJ, Thompson L, Kemp B, et al. Strengthening and optimal movements for painful shoulders (STOMPS) in chronic spinal cord injury: a randomized controlled trial. Phys Ther 2011;91:305-24.

24 Cadel L, DeLuca C, Hitzig SL, et al. Self-Management of pain and depression in adults with spinal cord injury: a scoping review. $J$ Spinal Cord Med 2020;43:280-97.

25 Schaffler J, Leung K, Tremblay S, et al. The effectiveness of selfmanagement interventions for individuals with low health literacy 
and/or low income: a descriptive systematic review. J Gen Intern Med 2018;33:510-23.

26 Stevens SL, Caputo JL, Fuller DK, et al. Physical activity and quality of life in adults with spinal cord injury. J Spinal Cord Med 2008;31:373-8.

27 Peduzzi P, Concato J, Kemper E, et al. A simulation study of the number of events per variable in logistic regression analysis. J Clin Epidemiol 1996;49:1373-9.

28 De Vos AS. Research at grass roots: a primer for the caring professions. Pretoria: Van Schaik, 2002.

29 Hearn JH, Cotter I, Fine P, et al. Living with chronic neuropathic pain after spinal cord injury: an interpretative phenomenological analysis of community experience. Disabil Rehabil 2015;37:2203-11.

30 Henning E, Van Rensburg W, Smit B. Finding your way in qualitative research. 2nd ed. Pretoria: Van Schaik Publishers, 2004.

31 Patton MQ. Qualitative evaluation and research methods: analysis, interpretation, and reporting. Newbury Park, California: Sage Publications, 2002.

32 Meshkat B, Cowman S, Gethin G, et al. Using an e-Delphi technique in achieving consensus across disciplines for developing best practice in day surgery in Ireland. J Hosp Adm 2014;3:1-8.

33 Eubank BH, Mohtadi NG, Lafave MR, et al. Using the modified Delphi method to establish clinical consensus for the diagnosis and treatment of patients with rotator cuff pathology. BMC Med Res Methodol 2016;16:56.

34 Widerström-Noga E, Biering-Sørensen F, Bryce TN, et al. The International spinal cord injury pain extended data set (version 1.0). Spinal Cord 2016;54:1036-46.

35 Mashola MK, Olorunju SAS, Mothabeng J. Factors related to hospital readmissions in people with spinal cord injury in South Africa. S Afr Med J 2019;109:107-11.
36 Curtis KA, Roach KE, Applegate EB, et al. Reliability and validity of the wheelchair user's shoulder pain index (WUSPI). Paraplegia 1995;33:290-3.

37 Bouhassira D, Attal N, Alchaar $\mathrm{H}$, et al. Comparison of pain syndromes associated with nervous or somatic lesions and development of a new neuropathic pain diagnostic questionnaire (DN4). Pain 2005;114:29-36.

38 Dijkers $M$. Comparing quantification of pain severity by verbal rating and numeric rating scales. J Spinal Cord Med 2010;33:232-42.

39 Bryce TN, Budh CN, Cardenas DD, et al. Pain after spinal cord injury: an evidence-based review for clinical practice and research. Report of the National Institute on disability and rehabilitation research spinal cord injury measures meeting. J Spinal Cord Med 2007;30:421-40.

40 Buelow AK, Haggard R, Gatchel RJ. Additional validation of the pain medication questionnaire in a heterogeneous sample of chronic pain patients. Pain Pract 2009;9:428-34.

41 Kirby RL, Smith C, Parker K, et al. The wheelchair skills program manual. Halifax, Nova Scotia, Canada: Dalhousie University, 2015. www.wheelchairskillsprogram.ca/eng/manual.php

42 Hill MR, Noonan VK, Sakakibara BM, et al. Quality of life instruments and definitions in individuals with spinal cord injury: a systematic review. Spinal Cord 2010;48:438-50.

43 Mothabeng DJ, Eksteen CA, Westaway M. Psychometric validation of the reintegration to normal living index in people living with spinal cord injuries. S Afr J Physiother 2012;68:29-32.

44 McClure P, Tate AR, Kareha S, et al. A clinical method for identifying scapular dyskinesis, part 1: reliability. J Ath/ Train 2009;44:160-4.

45 Borstad JD. Resting position variables at the shoulder: evidence to support a posture-impairment association. Phys Ther 2006;86:549-57. 